Canadian Oncology

Nursing Journal

Revue canadienne

de soins infirmiers

en oncologie

Volume 27, Issue 4 • Fall 2017

elSSN: 2368-8076 


\title{
The psychological impact of the rapid diagnostic centres in cancer screening: A systematic review
}

\author{
by Mina Singh, Christine Maheu, Teresa Brady, and Rachel Farah
}

\begin{abstract}
The purpose of this review is to assess the state of the literature and identify implications for nursing practice and future research on the psychological impact of rapid diagnostic centres (RDC) for women related to breast cancer. A systematic literature review was conducted on the topic and six studies were identified for data extraction and analysis. There is evidence that RDCs decrease short-term anxiety in women undergoing further cancer tests after cancer screening, and who receive a benign diagnosis. There is limited available research on the impact of anxiety on women who receive a diagnosis of cancer in RDCs, but some evidence showed that this sub-group had higher depression in the long term. Nurses need to be aware of the different needs of women undergoing further cancer screening tests after a cancer diagnosis and receiving these results in the same day.
\end{abstract}

Key words: rapid, same-day, one-stop, diagnosis, cancer, anxiety, stress

\section{INTRODUCTION}

B reast cancer is one of the most common malignancies diagnosed in Canadian women, with more than 22,000 new cases diagnosed in 2010 (Government of Canada, 2014). Studies have found that women undergoing investigation for breast cancer experience high levels of anxiety and uncertainty during the diagnostic phase, including the many women whose results are benign (Harding, 2013; Liao, Chen, Chen, $\&$ Chen, 2008; Meechan, Collins, Moss-Morris, \& Petrie, 2005; Morse et al., 2014). Women undergoing investigation also have

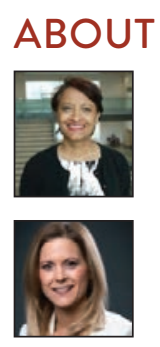

\footnotetext{
Mina Singh, BScN, MEd., PhD, Associate Professor, School of Nursing, Faculty of Health, York University, Toronto, $\mathrm{ON}$
}

Christine Maheu, BScN, MScN, PhD, Associate Professor, Ingram School of Nursing, Faculty of Medicine, McGill University, Montreal, QC

Teresa Brady, RN, BScN

Rachel Farah, RN, BScN

Address for correspondence: Mina Singh, BScN, MEd, PhD, Associate Professor, School of Nursing, Faculty of Health, York University, 326 HNES, 4700 Keele Street, Toronto, ON M3J 1P3

Email: minsingh@yorku.ca

DOI: $10.5737 / 23688076274348355$ unmet informational needs about the diagnostic process that may increase this uncertainty (Harding \& McCrone, 2013; Liao, Chen, Chen, \& Chen, 2007).

One-stop style of clinics became popular in the U.K. in the 1990 s, under the assumption that it is beneficial to women with benign disease to receive their assessment and results at one clinic visit (Association of Breast Surgery, 2005). Also in the 1990s, Canadian breast cancer initiatives were set to improve the integration of breast cancer services, and to reduce time to diagnosis (Olivotto et al., 2001). The rapid assessment style of clinic was brought about by patients' dissatisfaction with the fragmented process of screening, further testing and diagnosis that often took place between different locations and involved multiple appointments and wait times (Gray, 1997). The effectiveness of these rapid diagnostic clinics has been shown to decrease patient anxiety (Brocken, Prins, Dekhuijzen, \& Van der Heijden, 2012; Gagliardi, Grunfeld \& Evans, 2004) and increase patient satisfaction (Gagliardi, Grunfeld \& Evans, 2004). Considering that one in three women are likely to have a false-positive result from a screening mammogram if they undergo 10 screenings in their lifetime, it is easy to assume that rapid results of a benign outcome are beneficial to these women (Castells, Molins, \& Macià, 2006). However, there has been limited research and conflicting results in systematic reviews (Brocken, Prins, Dekhuijzen, \& Van der Heijden, 2012; Gagliardi, Grunfeld \& Evans, 2004) on the psychological impact that a rapid result may have on women undergoing breast cancer assessment.

\section{Purpose}

The purpose of this systematic review was to assess the state of the literature and identify implications for nursing practice, and future research, on the psychological impact of rapid diagnostic centres (RDC) on women screened for breast cancer.

The following research questions guided this review:

- What is the effect of receiving same-day results compared to usual care on psychological distress on women undergoing further cancer tests after screening?

- How is psychological distress measured for women undergoing further cancer tests after screening, and are these measures comparable across studies?

\section{Methods}

The design of this study is a quantitative systematic review. The Inclusion criteria for the search were studies with adult females (18 years and over), cancer screening, quantitative (RCT or quasi-experimental), English and French, full text only. The exclusion criteria were any studies with participants under 18 years old, studies with males, non-cancer diagnosis, qualitative type of studies, any language other than English and French, rapid genetic testing, intervention other than rapid diagnosis of cancer, and abstracts only. 
The databases included in the search were CINAHL, MedLine, Embase, Psycinfo, Cochrane, Joanna Briggs Institute, Web of Science, and Grey Literature Report. Key words used included "neoplasm" "cancer patients" "stress" "anxiety" "depression" "emotions" "uncertainty". Abstracts, titles, and keywords were searched with "rapid" and its synonyms, combined with "diagnosis" and its synonyms. Terms and strategies were adapted for the various databases. An overview of the search strategy is as follows:

S1: Cancer patients

S2: (rapid or emergency or fast or express or immediate or same-day or one-stop) adjacent or near (diagnos* or screen* or assess* or detect* or biopsy or test*)

S3: Stress or uncertainty or anxiety or fear or distress or coping or well-being or anger or depress*

S4: S1 AND S2 AND S3

The aim was to find both published and unpublished records. No limits were placed on year of publication. Results were limited to English and French language texts.

\section{Search outcome}

One thousand, one hundred and eighty-five records were initially retrieved from the databases and 845 remained after duplicates were removed. Initial screenings of these 845 records' titles and abstracts were done by two independent reviewers (T.B. and R.F.) to determine whether they met the inclusion criteria. Thirty-two records involving any malignancy, reference to the diagnostic process, and a psychological outcome were included for a second screening of full-text articles. Of these records, six were conference or poster abstracts. Of the remaining 23 articles, only 10 were determined to be RCTs or quasi-experimental with a comparison group. Two of these studies (Liao, Chen, Chen, Chen, \& Chen, 2009) (Liao, Chen, Chen, \& Chen, 2010) were excluded because the study did not focus specifically on the effects of a rapid diagnosis. Another (Wevers et al., 2013) was excluded because it focused on the psychological impact of rapid genetic screening for breast cancer patients and it was decided that the implications for a positive genetic test are different than the implications of a cancer diagnosis. Another article was excluded because it focused on the rapid results for prostate cancer (Wilkinson, Warren, Ramsden, Matthews, \& Chodak, 2008). Of the remaining articles, two were determined to focus on the same study, but were published a year apart, with additional outcomes added to the assessment six months into the initial study (Harcourt, Ambler, Rumsey, \& Cawthorn, 1998; Harcourt, Rumsey, \& Ambler, 1999). The additional measures of the second study were coping styles used, and were deemed not to be relevant to our research question and, therefore, that study was excluded. Of the five articles that remained, hand searching led to the inclusion of one other article eligible for review, leaving the final yield at six articles for the review (see Figure 1).

Figure 1: PRISMA STATEMENT - Flow Diagram

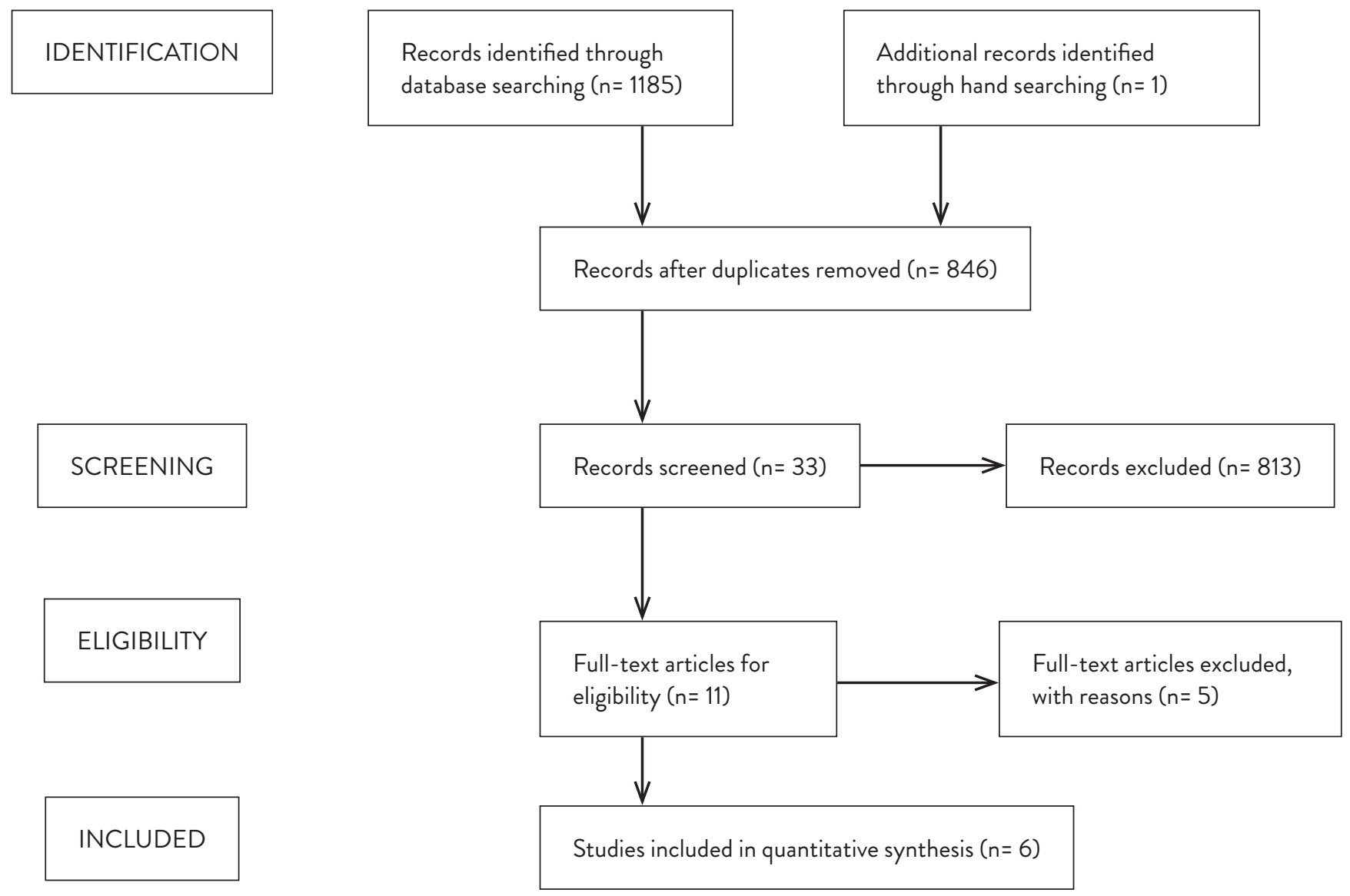




\begin{tabular}{|c|c|c|c|c|c|c|c|c|}
\hline $\begin{array}{l}\text { First } \\
\text { Author }\end{array}$ & Design & $\begin{array}{l}\text { Type of } \\
\text { Cancer }\end{array}$ & Intervention & Sample & $\begin{array}{l}\text { Time interval } \\
\text { measures }\end{array}$ & Measures & $\begin{array}{l}\text { Results related to } \\
\text { Measures of Interest }\end{array}$ & $\begin{array}{l}\text { Major limitations } \\
\text { related to research } \\
\text { question }\end{array}$ \\
\hline Barton & CCT & Breast & $\begin{array}{l}\text { Same-day } \\
\text { vs standard } \\
\text { care radiology } \\
\text { intervention }\end{array}$ & $\begin{array}{l}720 \text { women with false } \\
\text { positive mammograms }\end{array}$ & $\begin{array}{l}3 \text { weeks and } 3 \\
\text { months post } \\
\text { screening }\end{array}$ & $\begin{array}{l}\text { IES } \\
\text { HSC Anxiety } \\
\text { and Depression } \\
\text { subscale }\end{array}$ & $\begin{array}{l}\text { Significantly higher IES } \\
\text { scores at } 3 \text { weeks for } \\
\text { standard care }\end{array}$ & $\begin{array}{l}\text { Some women did not } \\
\text { realize they had a false- } \\
\text { positive result before } \\
\text { undergoing further } \\
\text { testing }\end{array}$ \\
\hline Dey & RCT & Breast & $\begin{array}{l}\text { Surgeon assessment, } \\
\text { further testing and } \\
\text { results same-day vs } \\
\text { the following week. }\end{array}$ & $\begin{array}{l}361 \text { women women with } \\
\text { clinical suspicion of breast } \\
\text { cancer }\end{array}$ & $\begin{array}{l}\text { Baseline, } 24 \\
\text { hours, } 3 \text { weeks, } \\
3 \text { months post } \\
\text { screening }\end{array}$ & $\begin{array}{l}\text { HADS anxiety } \\
\text { subscale } \\
\text { STAI }\end{array}$ & $\begin{array}{l}\text { Significant reduction in } \\
\text { anxiety for same-day } \\
\text { clinic at } 24 \text { hours only }\end{array}$ & $\begin{array}{l}50 \% \text { of women in the } \\
\text { control group still } \\
\text { received their results } \\
\text { on the same day as the } \\
\text { testing } \\
\text { No statistical } \\
\text { measurement } \\
\text { of demographic } \\
\text { differences }\end{array}$ \\
\hline Harcourt & RCT & Breast & $\begin{array}{l}\text { Testing with same- } \\
\text { day results vs results } \\
\text { a week later }\end{array}$ & $\begin{array}{l}583 \text { women referred } \\
\text { to clinic by general } \\
\text { practitioner for breast } \\
\text { lump; measurements } \\
\text { of malignant vs benign } \\
\text { groups }\end{array}$ & $\begin{array}{l}\text { Baseline, } 6 \text { days } \\
\text { and } 8 \text { weeks } \\
\text { post screening }\end{array}$ & $\begin{array}{l}\text { HADS } \\
\text { VAS }\end{array}$ & $\begin{array}{l}\text { Significantly higher } \\
\text { anxiety at } 6 \text { days in } \\
\text { benign delayed group } \\
\text { Significant interaction } \\
\text { between clinic type, } \\
\text { depression and final } \\
\text { diagnosis } \\
\text { Diagnosis of CA in same- } \\
\text { day had significantly } \\
\text { higher depression scores } \\
\text { at } 8 \text { weeks vs the delayed } \\
\text { group }\end{array}$ & $\begin{array}{l}\text { Follow-up of patients } \\
\text { diagnosed with cancer } \\
\text { only in clinic }\end{array}$ \\
\hline Naik & CCT & Cervical & $\begin{array}{l}\text { One-stop clinic vs } \\
\text { standard clinic }\end{array}$ & $\begin{array}{l}30 \text { women going } \\
\text { through colposcopy after } \\
\text { cervical smears with } \\
\text { borderline change or mild } \\
\text { dyskaryosis or both }\end{array}$ & $\begin{array}{l}\text { Measure of } \\
\text { change in } \\
\text { anxiety from } \\
\text { baseline to } \\
1 \text { week post } \\
\text { screening }\end{array}$ & $\begin{array}{l}\text { Scoring system } \\
\text { from } 0 \text { to } 4 \text { : } \\
\text { not anxious to } \\
\text { terrified }\end{array}$ & $\begin{array}{l}\text { Significantly greater } \\
\text { change in anxiety in one- } \\
\text { stop group (less anxiety) }\end{array}$ & $\begin{array}{l}\text { Small, uneven sample } \\
\text { size } \\
\text { No definition of anxiety } \\
\text { Absence of validated } \\
\text { tool }\end{array}$ \\
\hline Ubhi & CCT & Breast & $\begin{array}{l}\text { FNAB testing with } \\
\text { results the same day } \\
\text { or within a week; } \\
\text { One controlled for } \\
\text { surgeon approach }\end{array}$ & $\begin{array}{l}102 \text { women with clinical } \\
\text { suspicion of breast cancer; } \\
\text { measurements between } \\
\text { malignant and benign } \\
\text { groups }\end{array}$ & $\begin{array}{l}\text { Before and after } \\
\text { initial screening } \\
\text { consultation }\end{array}$ & $\begin{array}{l}\text { STAI-SSF } \\
\text { HADS }\end{array}$ & $\begin{array}{l}\text { Significant decrease in } \\
\text { anxiety post consultation } \\
\text { in one-stop benign } \\
\text { diagnosis group }\end{array}$ & $\begin{array}{l}\text { Small sample } \\
\text { Did not compare the } \\
\text { delayed group after } \\
\text { diagnosis } \\
\text { No demographic } \\
\text { description }\end{array}$ \\
\hline
\end{tabular}




\section{Data extraction}

Extraction from the articles was based on the following information: author, year, country of study, type of cancer, study design, sample size, measures and questionnaires used, time intervals between measures, major significant findings, and limitations relevant to this systematic review (see Table 1). Barton et al.'s (2004) study had multiple intervention groups that did not concern our research question, therefore data were only extracted on the groups of interest, although other aspects of the study were considered for our discussion.

\section{Quality appraisal}

The articles were appraised by two independent reviewers (T.B. and R.F.). We used the Effective Public Health Practice Project (EPHPP) Quality Assessment Tool for Quantitative Studies to determine the quality of the included studies (Effective Public Health Practice Project, 2009). Discrepancies were resolved with discussion, but agreement was high. Two studies were deemed to be weak, two moderate, and two strong (see Table 2).

\section{Synthesis}

Due to the heterogeneity of samples, measures, primary outcomes, study designs, and interventions, a meta-analysis was not feasible. A summary of results pertinent to the research question is presented in a narrative form to highlight relevant commonalities. Outcomes measured in the studies that did not pertain to the research question are summarized in Table 3.

\section{RESULTS}

\section{Characteristics}

All of the included studies concerned adult women undergoing screening or further investigation for cancer. The

Table 2: Summary of quality assessment table as per EPHPP tool

\begin{tabular}{|l|l|l|l|l|l|l|l|}
\hline First author & Selection Bias & Study Design & Confounders & Blinding & $\begin{array}{l}\text { Data collection } \\
\text { method }\end{array}$ & $\begin{array}{l}\text { Withdrawals and } \\
\text { dropouts }\end{array}$ & Global Rating \\
\hline Barton & Strong & Strong & Weak & Moderate & Moderate & Moderate & MODERATE \\
\hline Dey & Strong & Strong & Strong & Moderate & Moderate & Moderate & STRONG \\
\hline Harcourt & Strong & Strong & Strong & Moderate & Strong & Moderate & STRONG \\
\hline Lindfors & Weak & Moderate & Strong & Moderate & Weak & Not Applicable & WEAK \\
\hline Naik & Weak & Moderate & Weak & Weak & Weak & Moderate & WEAK \\
\hline Ubhi & Moderate & Strong & Weak & Moderate & Moderate & Strong & MODERATE \\
\hline
\end{tabular}

Table 3: Table of data extracted related to factors

\begin{tabular}{|c|c|c|c|}
\hline First Author & Other Factors & Measures & Results \\
\hline Lindfors & $\begin{array}{l}\text { Other factors associated } \\
\text { with increased anxiety after } \\
\text { a false positive results }\end{array}$ & $\begin{array}{l}\text { 1) Statistical comparison age } \\
\text { and stress } \\
\text { 2) Statistical comparison of } \\
\text { belief that abnormality may } \\
\text { mean cancer and stress score }\end{array}$ & $\begin{array}{l}\text { 1) Younger women (less than } 50 \text { years old) had significantly } \\
\text { greater overall stress than more than } 50 \text { group. } \\
\text { 2) Belief that the abnormality may mean cancer significantly } \\
\text { increases stress. }\end{array}$ \\
\hline Barton & $\begin{array}{l}\text { 1) Effectiveness of } \\
\text { educational intervention } \\
\text { pre-mammogram screening } \\
\text { to decrease anxiety in } \\
\text { women with false positive } \\
\text { mammograms } \\
\text { 2) Effect of false-positive } \\
\text { mammogram on anxiety }\end{array}$ & $\begin{array}{l}\text { 1) IES } \\
\text { 2)IES and HSC-A }\end{array}$ & $\begin{array}{l}\text { 1) No decrease in anxiety at } 3 \text { weeks post false-positive } \\
\text { mammogram between group receiving education intervention } \\
\text { and control. } \\
\text { 2) Significantly higher IES result at } 3 \text { weeks and } 3 \text { months for } \\
\text { false- positive group vs normal group. } \\
\text { Significantly higher HSC-A at } 3 \text { weeks for false-positive group } \\
\text { vs normal group. }\end{array}$ \\
\hline Harcourt & $\begin{array}{l}\text { Patient satisfaction with } \\
\text { style of clinic }\end{array}$ & VAS & $\begin{array}{l}\text { Significantly higher satisfaction in one-stop clinic group vs } \\
\text { two-stop clinic. }\end{array}$ \\
\hline \multicolumn{4}{|c|}{$\begin{array}{l}\text { RDC: rapid diagnostic clinic; IES: Impact of events scale; HSC-A: Hopkin's Symptoms Checklist- Anxiety subscale; VAS: Visual Analog } \\
\text { scale }\end{array}$} \\
\hline
\end{tabular}


population of three of the studies consisted of women undergoing investigation for suspected breast cancer after a referral and/or because of suspicious symptoms (Dey et al., 2002; Harcourt et al., 1998; Ubhi et al., 1996). Two of the studies consisted of women who received false positive results from screening mammograms (Barton et al., 2004; Lindfors, O'Connor, \& Parker, 2001) and the final study population was women undergoing colposcopy after having low-grade smear abnormalities (Naik et al., 2001). The ages of the participants ranged from 16-95 years. Four of the studies were conducted in the U.K. and two in the U.S.A. with the years of publication ranging from 1996 to 2004. Sample sizes ranged from 30 to 720 . Two of the studies were experimental and the remaining studies were controlled clinical trials.

\section{Rapid Diagnostic Clinic interventions}

All of the studies compared a group of participants receiving their results in a rapid, same-day manner to a group of participants receiving results in the typical, longer timeframe. Naik et al. (2001) defined the intervention as a one-stop colposcopy clinic where results of the punch biopsy were given at the first appointment with a median wait time of 120 minutes. The timeline for receiving results in the comparison group was unclear. Lindfors et al. (2001) were interested in women who had received mammograms, further investigatory work-up, and results in same day compared to those who had mammograms on one day, with notification of results and further appointments made for more work-up on a later day. Ubhi et al. (1996) defined the intervention as women getting fine needle aspiration biopsy results immediately after on the same day, compared with women returning for their results one week after the biopsy. Barton et al. (2004) compared women receiving immediate reading and results of mammograms as the intervention group with women receiving the results of their mammograms on a later date. A specific timeline for the comparison group was not stated. Dey et al. (2002) and Harcourt et al. (1998) had the same intervention group, which was women receiving the results of their investigatory work-up at the first clinic visit, compared to results given one week following the examinations, at a second visit.

\section{Assessment Measures}

There were a variety of tools of varying quality used to measure the outcomes of concern in these studies. This makes it difficult to compare across the studies. Four out of the six studies used well-known tools to measure the outcomes. The Hospital Anxiety and Depression Scale (HADS) was used in three of the studies and has been shown to be both reliable and valid (Harcourt et al., 1999) in this population. The HADS consists of two eight-item subscales (anxiety and depression), designed to be short enough to be given to patients attending an outpatient medical clinic (Zigmond \& Snaith, 1983). The HADS was designed to assess anxiety and depression, as well as assessing emotional illness regardless of the patient's somatic illness. This scale is usually given to patients to assess the level of anxiety or depression present not only in the clinic itself, but also within the week preceding the visit (Zigmond \& Snaith, 1983).
The State-Trait Anxiety Inventory (STAI) was used in two of the studies and is also a well validated and widely used tool in anxiety research (Ubhi et al., 1996). The STAI has been used to measure firstly the anxiety of a person's present experience (State Anxiety) and secondly, the anxiety present in the person's own personality trait (Trait Anxiety) (Tluczek, Henriques, $\&$ Brown, 2009). The researcher can, therefore, evaluate the changes in an individual's anxiety related to the transient experience he or she is subjected to versus the anxiety that the individual presents with as part of their personal characteristics (Tluczek et al., 2009). One out of those two studies used the STAI-SSF, a short six-question form of the original STAI (40 questions). The short-form STAI was used to allow for short-interval repeat measures when limited time is given for participants to answer the original form (Ubhi et al., 1996). In this same article, anxiety was measured before and after initial consultation at the clinic.

One study used the Hopkin's Symptom Checklist (HSC) anxiety and depression subscale and the Impact of Events Scale (IES), two validated scales (Barton et al., 2004). The complete HSC is a 58 items questionnaire divided into five symptom dimensions (Derogatis, Lipman, Rickels, Uhlenhuth, \& Covi, 1974). Barton et al. (2004) used the anxiety and depression 17-items subscale. The IES was created in order to measure the psychological distress of victims of a trauma (Sundin $\&$ Horowitz, 2002). The two subscales measure intrusion and avoidance towards the traumatic event and can be used as a measure of stress at different time interval (Sundin \& Horowitz, 2002). The two studies that were considered low quality based on the quality assessment used ordinal scales related to anxiety or stress with no clear validation or reliability (Lindfors et al., 2001; Naik et al., 2001).

\section{Outcomes \\ Operational definitions}

All of the studies were measuring anxiety in some way, given that in some articles the terms stress and anxiety were used interchangeably. For the purpose of data synthesis in this review, the term anxiety was used to encompass both stress and anxiety. Stress, as defined by U.S. National Library of Medicine (2014), "is a feeling of emotional or physical tension. It can come from any event or thought that makes you feel frustrated, angry, or nervous." Whereas the National Health Service (2015) defines anxiety as "a feeling of fear, unease, and worry. The source of these symptoms is not always known". In the context of awaiting the result of a cancer screening result, the authors felt that the two definitions could be considered as one outcome.

According to the DSM V, acute stress disorder associated with a traumatic event occurs between two days and four weeks after the event (Bryant, Friedman, Spiegel, Ursano, \& Strain, 2011). After this time, a chronic stress response diagnosis such as post-traumatic stress disorder can be made in patients meeting the criteria (Bryant et al., 2011). With this definition in mind, we can extrapolate a definition for shortterm versus long-term outcomes. Therefore, in this systematic review, we have decided to look at significant results 
from studies looking at anxiety, stress and depression outcomes up to six weeks post cancer screening as short-term outcomes and more than six weeks as long-term outcomes. This definition is also in accordance to the systematic review done by Brocken, Prins, Dekhuijzen, and Van der Heijden (2012) looking at distress of the diagnostic phase of cancer, as well as the influence of the rapid diagnosis pathway (Brocken et al., 2012).

\section{Short-term anxiety}

In the six articles reviewed, the main commonly shared outcome was the significant decrease in short-term anxiety in patients undergoing the one-stop diagnosis process (Barton et al., 2004; Dey et al., 2002; Harcourt et al., 1998; Lindfors et al., 2001; Naik et al., 2001; Ubhi et al., 1996). It is important to point out that most of our articles have looked at women with false-positive results; therefore, they were not diagnosed with cancer at the end of the screening process. Only two articles out of the six also looked at the difference between women receiving a cancer diagnosis versus no diagnosis of cancer. In the reporting of the short-term findings, we are only comparing the intervention of the clinic itself regardless of the subjects' final diagnosis. The difference in the women's baseline anxiety levels was non-significant for the intervention and control group for all four studies that measured baseline anxiety (Dey et al., 2002; Harcourt et al., 1998; Naik et al., 2001; Ubhi et al., 1996).

\section{Long-term anxiety}

Only three of the six studies measured long-term anxiety levels post cancer screening. Measures of anxiety were taken at two months (Harcourt et al., 1998) and three months (Barton et al., 2004; Dey et al., 2002). In these three studies, there were no significant differences in anxiety levels between the sameday diagnosis group and the delayed group. Again, the same considerations as in the short-term outcomes apply. These results were found comparing the clinic type without controlling for the subjects' final diagnosis.

\section{Effect of the intervention among women who were diagnosed with cancer}

Some of the studies excluded women who, ultimately, received a cancer diagnosis (Barton et al., 2004; Lindfors et al., 2001) and others had a small proportion of their sample with a cancer diagnosis, making inferences difficult. While Dey et al. (2002) included the data that $13.3 \%$ of their sample received a breast cancer diagnosis, they did not report on the differences in psychological outcomes for this group. The same study did indicate that there was a significantly higher level of cancer diagnoses in women who declined to participate in the study. Only two of the studies included and compared the two processes in women who received a definitive cancer diagnosis. Harcourt et al. (1998) found that higher anxiety was present in patients diagnosed with breast cancer regardless of the style of clinic attended at the six-day time point, compared to women who had received benign outcomes. This difference is despite the fact that at the six-day time point, many women in the two-stop clinic had not yet received their diagnosis. Depression was also measured in this study and was found to be significantly higher in women diagnosed with cancer in the one-stop clinic compared with those diagnosed in the two-stop clinic at the eight-week time point. Ubhi et al. (1996) found no significant difference in anxiety in women diagnosed with cancer at the one-stop versus the two-stop clinic in the short term, and outcomes were not measured in the long term. However, it was a very small portion of the sample that was diagnosed with cancer, and outcomes were measured at initial visit only for both groups, so those allocated to have two clinic visits had not yet received their results.

\section{DISCUSSION}

This review aimed to identify the psychological outcomes for women who receive the results of their cancer screening on the same day compared with the usual pathway. The clearest finding was that all of the studies in the review, regardless of measures used, found significantly lower anxiety levels in women who received their results on the same day in the short-term. This supports the findings of the systematic review completed by Brocken, Prins, Dekhuijzen, and Van der Heijden, (2012). The three studies that measured long-term anxiety found no group differences. In one of the studies (Barton et al., 2004), the anxiety level was reduced as a result of the immediate reading of the mammogram results. Anxiety was reduced on site, as women with abnormal results who received their immediate radiology review have less anxiety than women who did not receive an immediate reading. This shows that rapid evaluation of mammogram screening may be an effective approach in decreasing early level of anxieties. However, at three-month follow-up the anxiety scores were similar for all groups regardless of the intervention received. This suggests that the benefits of a short-term reduction in anxiety do not have lasting effects in terms of long-term anxiety. The outcome in this study (Barton et al., 2004) was consistent with that of Lindfors et al. (2001), as both were based on false-positive mammogram results. Women in the immediate workup group (that is received the results on site) reported their experience as a little stressful while the other delayed workup group (returned for later evaluation) had a moderate level of stress. Age also had a significant effect on the level of stress, as women who were younger than 50 experienced greater levels of stress than older women (Lindfors et al., 2001).

Of the studies using the HADS tool, only one found significant differences in depression scores between groups, and this was amongst the sub-group of women with a breast cancer diagnosis, eight weeks later. It would seem that anxiety is more associated with the short-term uncertainty of women undergoing the screening process, whereas depression is more associated with the longer-term effects of a cancer diagnosis. This is consistent with constructs of anxiety and depression wherein the difference between the two is that anxiety is usually seen as a reaction to a potential future threat, whereas depression is more of a reaction to a past threat, or actual loss (Dobson, 1985). 
Compared to women receiving the 'all-clear', one would expect that there would be a significant difference in terms of psychological outcomes in women with a malignant diagnosis. It was surprising, then, to find that only two studies made the distinction of a benign or malignant result between the two groups with respect to the style in which results were received. In one of the studies (Ubhi et al., 1996) involving two groups in which one group received the result immediately and the other group had delayed communication of results; anxiety was reported to be high in both groups at the initial visit. However, women with malignant results had higher level of anxiety compared to those with benign results. This further shows a significant reduction in anxiety as a result of immediate communication of benign diagnosis. It is worth mentioning that the sample size of the malignant group in this study was very small.

Since the outcome of breast cancer would not be known when recruiting participants, large sample sizes would be necessary to have adequate power to make inferences about women diagnosed in one style of clinic versus the other. The fact that in Dey et al.'s (2002) study there was a significantly higher number of women with a cancer diagnosis in the non-participants may indicate that women with cancer somehow knew that their chances of a diagnosis were high and, therefore, were more distressed and less likely to participate in the study. A cohort study not included in this review was interested in the implications of a one-stop clinic for women who were diagnosed with breast cancer, but they ended up with only $1.4 \%$ of their sample receiving a malignant outcome and, therefore, were unable to make inferences about the implications for that sub-population (Vedhara et al., 2001). The same study suggested that the fact that presence of malignant disease is unknown prior to the clinic visit could present barriers for ensuring adequate support is available to these women. It seems that the same challenges that make the sub-group of women diagnosed with cancer difficult to study may also be challenges for providing appropriate psychosocial care.

\section{IMPLICATIONS FOR RESEARCH}

From the results of our systematic review, implications for research and nursing practice are important to highlight. First, the costs versus benefits of a rapid diagnosis clinic need to be looked at in order to justify the introduction of such clinics. Also, as stated in the discussion, future research should include samples of women receiving a positive cancer diagnosis in the rapid diagnostic pathway, since they may, in fact, suffer from negative psychological impacts from RDCs. Some studies have also included other measures of interest that may have potential implications for practice but were outside the scope of this systematic review. These measures of interest include the effect on demographic factors such as age or family history of cancer, the effect of an education intervention on coping strategies and on the reasons of an abnormal mammogram (Table 3).

\section{IMPLICATIONS FOR NURSING}

The development of rapid diagnostic clinics has many implications for nursing practice. Nurses need to be aware of the different needs of patients undergoing further cancer tests after a cancer diagnosis and receiving these results in the same-day. The implication for nurses in the development and implementation of appropriate educational and anxiety assessment tools is important, as well as appropriate resources for the short-term follow-up of patients with false-positive results. Harcourt et al. (1999) describe that women receiving a final benign result wished they had more time to discuss their results at the clinic. Therefore, the proper time and type of professional resources needed to decrease short-term anxiety would be an interesting area of nursing practice research. The detrimental effect of anxiety is crucial, thus there is a need to provide or increase psychosocial support for group of women diagnosed with cancer at the one-stop clinic. Health education in coping strategies could be developed and integrated for women attending the clinic so that they can benefit from strategies to reduce anxiety associated with a cancer diagnosis.

\section{LIMITATIONS}

The studies included in this review had a few limitations that need to be mentioned. Many studies had small sample sizes with less than 100 participants. Power calculations were done in only two out of the six studies (Barton et al., 2004; Dey et al., 2002). Also, none of the studies defined the key terms "anxiety" and "stress" and used those terms interchangeably. Finally, the IES scale used by Barton et al. (2004) was created to measure post-traumatic stress related to a traumatic event, but may not have been the best tool in this type of study. Women in the false-positive group of this study reported no anxiety according to the IES in 52\% of cases (Barton et al., 2004). Therefore, the anxiety lived by women going through the cancer screening process may not have been captured by this tool.

This systematic review also has limitations in terms of the heterogeneity of samples, tools and quality of the studies. Due to the scarce amount of strong, homogeneous and controlled studies, they have all been included in this systematic review in order to capture all the experimental literature on the topic of rapid diagnostic pathways and psychological impact. Four out of the six studies are from the United Kingdom and two are from the United States of America. Cultural and societal differences may limit the generalization that can be made in the current Canadian perspective. Unfortunately, the limited amount of literature currently available limited our review to an all-female and mainly breast cancer sample.

\section{CONCLUSION}

The salient finding of this systematic review is that there is psychological benefit for RDCs on women with benign outcomes with a short-term reduction in anxiety. Timely reading of cancer screening results and communication contributed to reduced anxiety. There is limited research on the long-term outcomes or for women with cancer diagnoses. 


\section{REFERENCES}

Association of Breast Surgery. (2005). Guidelines for the management of symptomatic breast disease. European Journal of Surgical Oncology (EJSO), 31, Supplement 1(0), 1-21. doi:http://dx.doi. org/10.1016/j.ejso.2005.02.006

Barton, M.B., Morley, D.S., Moore, S., Allen, J.D., Kleinman, K.P., Emmons, K.M., \& Fletcher, S.W. (2004). Decreasing women's anxieties after abnormal mammograms: A controlled trial. J. Natl. Cancer Inst., 96(7), 529-538.

Brocken, P., Prins, J.B., Dekhuijzen, P.N.R., \& Van der Heijden, H.F.M. (2012). The faster the better? A systematic review on distress in the diagnostic phase of suspected cancer, and the influence of rapid diagnostic pathways. Psycho-Oncology, 21(1), 1-10. doi:10.1002/pon.1929

Bryant, R.A., Friedman, M.J., Spiegel, D., Ursano, R., \& Strain, J. (2011). A review of acute stress disorder in DSM-5. Depression and Anxiety, 28(9), 802-817. doi:10.1002/da.20737

Castells, X., Molins, E., \& Macià, F. (2006). Cumulative false positive recall rate and association with participant related factors in a population based breast cancer screening programme. Journal of Epidemiology and Community Health, 60(4), 316-321. doi:10.1136/ jech.2005.042119

Derogatis, L.F., Lipman, R.S., Rickels, K., Uhlenhuth, E.H., \& Covi, L. (1974). The Hopkins Symptom Checklist (HSCL): A self-report symptom inventory. Behavioral Science, 19(1), 1-15.

Dey, P., Bundred, N., Gibbs, A., Hopwood, P., Baildam, A., Boggis, C., ... Dixon, J.M. (2002). Costs and benefits of a one stop clinic compared with a dedicated breast clinic: Randomised controlled trial. BMJ, 324(7336), 507.

Dobson, K.S. (1985). The relationship between anxiety and depression. Clinical Psychology Review, 5(4), 307-324. doi:http:// dx.doi.org/10.1016/0272-7358(85)90010-8

Effective Public Health Practice Project. (2009). Quality Assessment tool for Quantitative Studies. Retrieved from http://www.ephpp.ca/tools. html

Gagliardi, A., Grunfeld, E., \& Evans, W.K. (2004). Evaluation of diagnostic assessment units in oncology: A systematic review. $J$ Clin Oncol., 22(6),1126-35.

Government of Canada. (2014, July 10). Cancer, new cases, by selected primary site of cancer, by sex. Retrieved from http://www.statcan. gc.ca/tables-tableaux/sum-som/101/cst01/hlth61-eng.htm

Gray, C. (1997). One-stop care at breast centre another sign of patients' increasing influence. Canadian Medical Association Journal, 157(10), 1419-1420.

Harcourt, D., Ambler, N., Rumsey, N., \& Cawthorn, S.J. (1998). Evaluation of a one-stop breast lump clinic: A randomized controlled trial. The Breast, 7(6), 314-319.

Harcourt, D., Rumsey, N., \& Ambler, N. (1999). Same-day diagnosis of symptomatic breast problems: Psychological impact and coping strategies Psychology, Health \& Medicine, 4(1), 57-71.

Harding, M.M. (2013). Predictors of distress during the breast diagnostic period. West Virginia University Libraries.

Harding, M.M., \& McCrone, S. (2013). Experiences of non-navigated women undergoing breast diagnostic evaluation. Clinical Journal of Oncology Nursing, 17(1), E8-E12.

Liao, M.-N., Chen, M.-F., Chen, S.-C., \& Chen, P.-L. (2007). Healthcare and support needs of women with suspected breast cancer. Journal of Advanced Nursing, 60(3), 289-298.

Liao, M.-N., Chen, M.-F., Chen, S.-C., \& Chen, P.-L. (2008). Uncertainty and anxiety during the diagnostic period for women with suspected breast cancer. Cancer Nursing, 31(4), 274-283.
Liao, M.-N., Chen, P.-L., Chen, M.-F., \& Chen, S.-C. (2010). Effect of supportive care on the anxiety of women with suspected breast cancer. Journal of Advanced Nursing, 66(1), 49-59.

Liao, M.-N., Chen, P.-L., Chen, M.-F., Chen, S.-C., \& Chen, Y.-H. (2009). Supportive care for Taiwanese women with suspected breast cancer during the diagnostic period: Effect on healthcare and support needs. Oncology Nursing Forum, 36(5), 585-592.

Lindfors, K.K., O'Connor, J., \& Parker, R.A. (2001). False-positive screening mammograms: Effect of immediate versus later work-up on patient stress. Radiology, 218(1), 247-53.

Meechan, G.T., Collins, J.P., Moss-Morris, R.E., \& Petrie, K.J. (2005). Who is not reassured following benign diagnosis of breast symptoms? Psychooncology, 14(3), 239-46.

Morse, J., Pooler, C., Vann-Ward, T., Maddox, L., Olausson, J., RocheDean, M., .... Martz, K. (2014). Awaiting diagnosis of breast cancer: Strategies of enduring for preserving self. Oncology Nursing Forum, 41(4), 350-9.

Naik, R., Abang-Mohammed, K., Tjalma, W.A., Nordin, A., de Barros Lopes, A., Cross, P.A., ... Monaghan, J.M. (2001). The feasibility of a one-stop colposcopy clinic in the management of women with low grade smear abnormalities: A prospective study. Eur J Obstet Gynecol Reprod Biol., 98(2), 205-8.

National Health Service (2015). Stress, anxiety, and depression. Retrieved from http://www.nhs.uk/Conditions/stress-anxietydepression/Pages/understanding-panic.aspx

Olivotto, I.A., Bancej, C., Goel, V., Snider, J., McAuley, R.G., Irvine, B., .... Caines, J.S. (2001). Waiting times from abnormal breast screen to diagnosis in 7 Canadian provinces. CMAJ: Canadian Medical Association Journal, 165(3), 277-283.

Sundin, E.C., \& Horowitz, M.J. (2002). Impact of Event Scale: psychometric properties. The British Journal of Psychiatry, 180(3), 205-209. doi:10.1192/bjp.180.3.205

Tluczek, A., Henriques, J., \& Brown, R. L. (2009). Support for the reliability and validity of a six-item state anxiety scale derived from the State-Trait Anxiety Inventory. Journal of Nursing Measurement, 17(1), 19-28. doi:D-NLM:NIHMS140167

Ubhi, S.S., Wright, S., Clarke, L., Black, S., Shaw, P., Stotter, A., \& Windle, R. (1996). Anxiety in patients with symptomatic breast disease: Effects of immediate versus delayed communication of results. Annals of the Royal College of Surgeons of England, 78, 466-469.

U.S. National Library of Medicine. (2014). Stress and your health. Retrieved from https://medlineplus.gov/ency/article/003211.htm

Vedhara, K., Bennett, P.D., Brooks, E., Gale, L., Munnoch, K., Schreiber-Kounine, C., ... Farndon, J. (2001). Risk factors for psychological morbidity in women attending a one-stop diagnostic clinic with suspected breast disease. Psychology \& Health, 16(2), 179-190.

Wevers, M., Ausems, M., Bleiker, E., Rutgers, E., Witkamp, A., Hahn, D., ... Aaronson, N. (2013). Psychosocial impact of rapid genetic counseling and testing in breast cancer patients: Findings from a RCT. Psycho-Oncology, 22, 25-26.

Wilkinson, S., Warren, K., Ramsden, A., Matthews, A., \& Chodak, G. (2008). Do "rapid" PSA assays reduce anxiety and stress of prostate cancer patients undergoing regular review? A prospective evaluation. Urology, 71(4), 67-72.

Zigmond, A., \& Snaith, R.P. (1983). The hospital anxiety and depression scale. Acta Psychiatrica Scandinavica, 67, 361-370. 